\title{
Polygalacturonase-Inhibiting Proteins Can Function as Activators of Polygalacturonase
}

\author{
G. Kemp, ${ }^{1}$ L. Stanton, ${ }^{1}$ C. W. Bergmann, ${ }^{1}$ R. P. Clay, ${ }^{2}$ P. Albersheim, ${ }^{1}$ and A. Darvill ${ }^{1}$ \\ ${ }^{1}$ Complex Carbohydrate Research Center and Department of Biochemistry and Molecular Biology, University of Georgia, \\ 315 Riverbend Road, Athens, Georgia 30602-4712, U.S.A.; ${ }^{2}$ Department of Biology, University of West Georgia, 1600 Maple \\ St, Carrolton, Georgia, 30118, U.S.A.
}

Submitted 29 December 2003. Accepted 1 April 2004.

\begin{abstract}
The interaction between fungal endopolygalacturonases (EPGs) and polygalacturonase-inhibiting proteins (PGIPs) found in plant cell walls has been well established. The typical EPG/PGIP interaction is characterized by high affinity, reversibility, and a 1:1 stoichiometry that results in lowering the catalytic rate of a particular endopolygalacturonase by up to $\mathbf{9 9 . 7 \%}$. Various EPG and PGIP isoforms and glycoforms have been isolated and characterized, and combinations of EPGs and PGIPs demonstrate a range of enzyme inhibition. EPG/PGIP interactions have prompted many researchers to suspect the involvement of these proteins in the production of specific signals (oligosaccharins) during plant pathogenesis. We have recently reported on initial studies in our laboratory indicating that, for certain EPG/PGIP combinations, the specific activity of EPG is increased beyond that characteristic of the enzyme alone. In this paper, we present a detailed analysis of the product of the interaction of native Phaseolus vulgaris PGIP-2 with five EPGs from Aspergillus niger, namely PGI, PGII, PGA, PGB, and PGC in the presence of homogalacturonan. We demonstrate that for PGA and PGC, the interaction with PGIP-2 may result in either inhibition or activation in a manner that is $\mathrm{pH}$ dependent. This data suggests the need for a reevaluation of the conventional description applied to PGIPs; suggestions include polygalacturonase-binding protein and polygalacturonase-modulating protein.
\end{abstract}

Additional keywords: plant defense, protein-protein interaction.

Endopolygalacturonases (EPGs) provide much of the pectindegrading activity of phytopathogenic fungi and are among the first degradative enzymes to be secreted upon fungal infection of plants (Cooper 1983; Jones et al. 1972). EPGs have been shown to function in either a random or processive manner, based on the degrees of polymerization (DPs) and quantities of oligogalacturonides (OGAs) released through enzymatic action (Benen et al. 1996; Cook et al. 1999). EPGs hydrolyze nonesterified regions of wall-bound homogalacturonan, which serves to expose nonpectic cell wall polymers to the action of other exo- and endoglycanases, including the cellulases and hemicellulases (Knogge 1996). The outcome of in vitro enzymatic hydrolysis of polymeric homogalacturonan by EPGs is the formation of a range of OGAs of varying sizes, a subpopu-

\section{Stanton and G. Kemp contributed equally to this work.}

Corresponding author: C. W. Bergmann; Telephone: 706-542-4487; Fax: 706-542-4412; E-mail: cberg@ccrc.uga.edu lation of which (DPs of 9 to 16) has been demonstrated to elicit various plant defense responses in bioassays (Darvill et al. 1992).

During pathogenesis, there is the potential for interaction between fungal EPGs and plant cell wall-located inhibitors of EPGs known as polygalacturonase-inhibiting proteins (PGIPs) (Cervone et al. 1989; Darvill et al. 1994). PGIPs are soluble glycoproteins found in the extracellular matrix of dicotyledonous and monocotyledonous plants (De Lorenzo and Ferrari 2002; Favaron et al. 1994; Kemp et al. 2003; Lafitte et al. 1984). Evidence to date indicates that PGIPs form high-affinity complexes with EPGs in a reversible, stoichiometrically defined manner. The rate of hydrolysis of homogalacturonan by an EPG/PGIP complex has been shown, depending upon the source of the EPG and PGIP, to be between one and two orders of magnitude slower than that effected by the uncomplexed EPG alone (Cook et al. 1999). This observation suggests that the inhibition of EPGs by PGIPs may not only slow down the rate at which EPGs fragment and solubilize pectic wall polymers but, in doing so, may also extend the lifetime of biologically active OGAs (i.e., fragments of homogalacturonan) released from the cell wall by the action of the EPGs. Since OGAs have been implicated as elicitors of a number of defense responses in plants, extending their lifetime likely affords the plant more time to mount a successful defense response than would be the case in the absence of these PGIPs (Cervone et al. 1989; Côté and Hahn 1994).

EPGs from a single strain of fungus appear to exist in a variety of isoforms; multiple isoforms have been demonstrated in a number of fungi (Centis et al. 1997; Di Pietro and Roncero 1996; Sharrock and Labavitch 1994; Wubben et al. 1999). Additionally, these EPG isoforms may each be expressed in multiple glycoforms and may vary in their modes of action (random or processive) as well as in their abilities to interact with and be inhibited by PGIPs (Cook et al. 1999; Stotz et al. 2000). This variability suggests that the mode of action of cleavage for a particular fungal EPG (Benen et al. 1996; Cook et al. 1999), coupled with its particular susceptibility to inhibition by PGIPs, are critical factors that help determine the virulence of a potential fungal pathogen.

Among the numerous isoforms and glycoforms of pectindegrading enzymes, evidence indicates that some variants, such as Aspergillus niger PGI and PGII, are inducible according to either physiological or nutritional factors, or both, while others appear to be constitutively produced. A. niger encodes a family of seven different EPGs, six of which have been characterized (Pařenicová et al. 1998, 2000); two of these isoforms, termed PGA and PGB, are constitutively expressed (Pařenicová et al. 2000). P2c, the constitutively expressed EPG of the cotton 
pathogen Aspergillus flavus, has been directly related to the aggressiveness of the pathogen (Shieh et al. 1997). A recent study indicates the majority of Botrytis cinerea EPGs to be constitutive (Wubben et al. 1999). The observations of both inducible and constitutively produced EPGs in a given fungus suggest the possibility of different functionalities for these molecules within the sphere of host-pathogen interactions.

PGIP genes have been cloned from several species (Toubart et al. 1992; Stotz et al. 1994). Sequence analysis and a recent crystal structure of Phaseolus vulgaris PGIP-2 (Di Matteo et al. 2003) demonstrate that they encode proteins with a leucinerich repeat (LRR) structural motif. LRR are characteristic of protein-protein interactions and have been identified as conserved features in many disease resistance genes (Jones and Jones 1997), suggesting that PGIPs may be involved in pathogen recognition (De Lorenzo et al. 2001). PGIPs from a range of species often show considerable homology; yet individual isoforms appear to exhibit a degree of specificity with respect to the EPGs that they inhibit in vitro (Cook et al. 1999; Sharrock and Labavitch 1994; Stotz et al. 2000). In addition to differences in degree of inhibition for various EPG/PGIP pairings, the type of inhibition has been reported as both competitive and noncompetitive, indicating that the location of the interaction may vary (Stotz et al. 2000). Evidence has been presented that the PGIP binds at either the substrate binding site (Frederici et al. 2001) or the underside of the EPG (King et al. 2002). No conclusive evidence to support either possibility exists at this time. At present, it is not known whether specificity of inhibition in vivo is a contributing factor in determining host-cultivar and pathogen-race specificity, as experiments have only addressed in vitro systems.

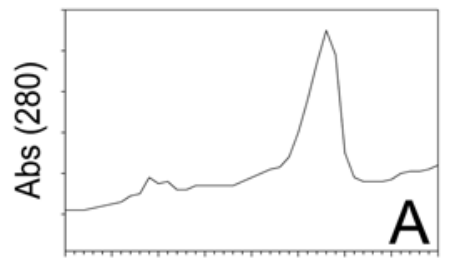

$\begin{array}{lllllllll}10 & 15 & 20 & 25 & 30 & 35 & 40 & 45 & 50\end{array}$
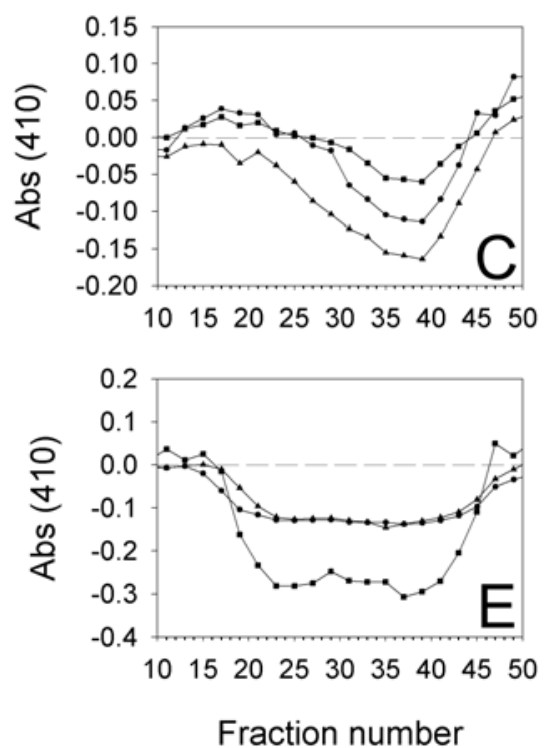
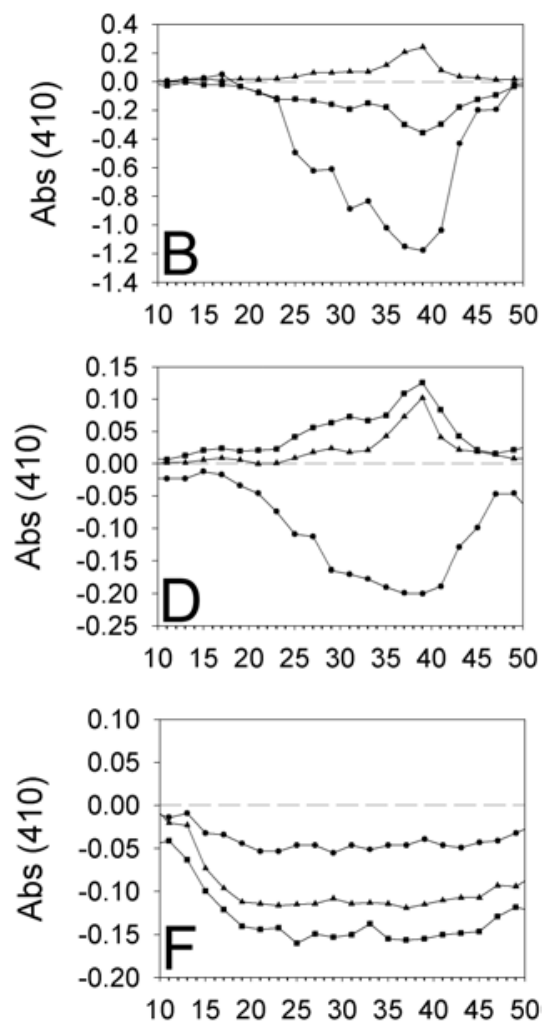

Fraction number
As part of an ongoing study of EPGs and PGIPs, we have recently obtained evidence that PGIPs may act as activators of some EPGs produced by A. niger (Bergmann et al. 2001). Microenvironmental parameters of the apoplast, such as variation in $\mathrm{pH}$, appear to have the potential to alter the outcome of some EPG and PGIP interactions from inhibition to activation. These observations suggest a more complex regulatory mechanism in plant pathogenesis than was previously contemplated for EPG and PGIP interactions. In support of these observations, in this paper, we present the interaction of native $P$. vulgaris PGIP-2 with five PGs from A. niger.

\section{RESULTS}

Previous studies have always shown that PGIPs either inhibit or have no effect on fungal EPGs (Cervone et al. 1989; Cook et al. 1999; Favaron et al. 1994; Lafitte et al. 1984; Sharrock and Labavitch 1994; Stotz et al. 1994, 2000; Toubart et al. 1992). In this study, the interactions of $P$. vulgaris PGIP-2 with the constitutive EPGs of $A$. niger (a nonpathogen of $P$. vulgaris), PGA, and PGB, as well as with three inducible A. niger EPGs, PGI, PGII, and PGC, were evaluated and compared. The results reported were all obtained using PGIP-2 isolated from cv. Canellino. Similar results (not shown) were obtained with PGIP-2 isolated from cv. Pinto. For the purpose of this study, PGIP-2 is defined as that PGIP isolated on an affinity column of Fusarium moniliforme EPG, as described by Desiderio and associates (1997). A tracing of the final purification step of PGIP-2 on a Hi-Trap-S cation exchange column is given in Figure 1A.

The purified PGIP-2 and the EPGs tested (discussed below) were homogeneous (except for glycosylation), as indicated by

Fig. 1. A, Chromatogram of Phaseolus vulgaris polygalacturonase-inhibiting protein (PGIP-2) following purification on a cation exchange (Hi-Trap-S) cartridge. B, Profile with absorbances following PAHBAH ( $p$-hydroxybenzoic acid hydrazide) assays for polygalacturonase A (PGA)/PGIP-2, relative to free PGA at pH 4.2 (filled circle), $\mathrm{pH} 4.75$ (filled square), and pH 5.0 (filled triangle). A negative value indicates inhibition, while a positive value indicates activation. The same data is presented for $\mathbf{C}$, PGB; D, PGC; E, PGI; and F, PGII. 
Matrix-assisted laser desorption-ionization time of flight mass spectrometry (MALDI-TOF MS) (Fig. 2). The enzymatic activity of the various EPGs on homogalacturonan substrate show differing $\mathrm{pH}$ optimums using reducing sugar analysis, with PGA and PGC having an optimal pH of 4.2, PGI and PGII at $\mathrm{pH} 4.75$, and $\mathrm{PGB}$ requiring a less acidic $\mathrm{pH}$ of 5.5 for optimal activity (Fig. 3). This is in agreement with previously reported data (Benen et al. 1999; Pařenicová et al. 2000).

Following addition of pure PGIP-2 (Fig. 1A, fraction 39), the activity of PGI, PGII, and PGB are greatly reduced at all $\mathrm{pH}$ levels (Fig. 3B, D, and E). In contrast, at higher $\mathrm{pH}$ levels, the addition of PGIP-2 to PGA or PGC reveals an activation phenomenon (Fig. 3A and C), with the plots of the relative activities in the presence and absence of PGIP-2 crossing over, representing a change from inhibition to activation. The activation is highly reproducible but small in comparison with the level of the inhibition. For example, an $85 \%$ inhibition is seen for the PGA/PGIP-2 complex at $\mathrm{pH} 4.2$, while a $19 \%$ activation is observed at $\mathrm{pH} 5.0$ (Fig. 3A).

The results from the reducing sugar assays are presented in Figures 1B, 2, 3, and 4. Every other fraction from the cation exchange column (Fig. 1A) was tested at $\mathrm{pH} 4.2,4.75$, and 5.0 against the various EPGs. The absorbances for the EPG/PGIP2 complexes are normalized relative to the activity of the EPGs by themselves. This data clearly demonstrates that the PGA/PGIP-2 and PGC/PGIP-2 complexes undergo a transition from inhibition to activation as the $\mathrm{pH}$ increased (Fig. 1B and D). Both PGA and PGC were activated by native bean PGIP-2 at $\mathrm{pH} 5.0$, the approximate $\mathrm{pH}$ of the plant cell wall, with $\mathrm{PGC}$ showing a maximum activation at $\mathrm{pH} 4.75$ (Fig.1B and D). The PGA/PGIP-2 interaction reverted to inhibition at $\mathrm{pH} 4.75$ and below, as did the interaction between PGIP-2 and PGC at pH 4.2 (Fig. 1B and D). In contrast, the interactions of PGB, PGI, and PGII with PGIP-2 demonstrated the well-established inhibition of enzyme activity throughout the range of $\mathrm{pH}$ levels tested (Fig. 1C, E, and F).

The data from the reducing sugar assays presented in Figures 1 and 3 were confirmed by high performance anion exchange chromatography (HPAEC) and are represented by selected profiles of 1-h digests of homogalacturonan by PGA, PGB, and PGC in the presence or absence of PGIP-2 at pH 4.2 and 5.0 (Fig. 4). Each peak represents an oligomer of galacturonic acid, the sizes of which are indicated in Figure 4. For each enzyme and enzyme/inhibitor combination, an increase in the amount of the smaller GalA oligomers in one profile relative to another demonstrated increased levels of hydrolytic activity.

\section{DISCUSSION}

PGIPs have traditionally been viewed as inhibitors of EPGs. This inhibition of EPG by PGIP has been demonstrated in vitro for A. niger PGII to have a $\mathrm{pH}$ optimum near 5.0 (Cervone et al. 1987). EPG/PGIP combinations are generally tested in the $\mathrm{pH}$ range of 4.6 to 5.3 (Favaron et al. 1994; Hoffman and Turner 1982; Lafitte et al. 1984). In planta, fungal cell-walldegrading enzymes (CWDE) initially encounter an apoplastic environment generally characterized by a $\mathrm{pH}$ in the range of 4.5 to 5.0 (Yakoby et al. 2000), with localized microdomains
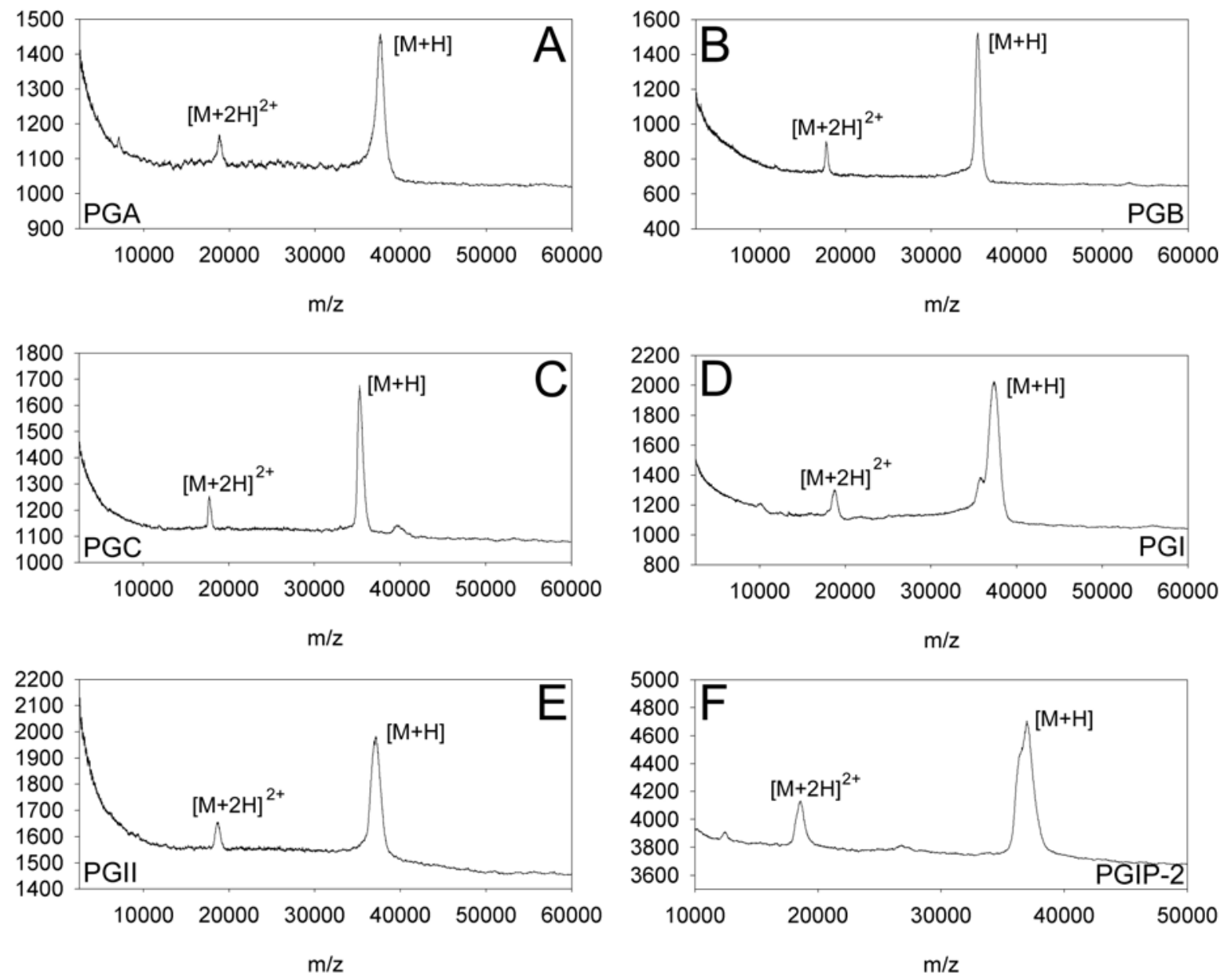

Fig. 2. Matrix-assisted laser desorption mass spectrometer profiles of the different endopolygalacturonases used, as well as of Phaseolus vulgaris polygalacturonase-inhibiting protein (PGIP)-2. A, PGA; B, PGB; C, PGC; D, PGI; E, PGII; and F, PGIP-2. Doubly and triply charged ions are indicated. 
of $\mathrm{pH}$ that may vary significantly above or below this range. The data presented in this paper demonstrates that at $\mathrm{pH} 4.75$ or above, different EPGs may be either inhibited or activated by the same PGIP.

The enzymes PGA and PGB are constitutively expressed by A. niger (Pařenicová et al. 2000) and are thus present when the penetrating fungus can be presumed to have had a minimum of time to effect a change in the $\mathrm{pH}$ of the apoplastic environment of normal plant tissues, for example, through the production of enzymes such as pectin methylesterase (PME). During normal liquid culture conditions, PGA and PGB are not produced by wild-type $A$. niger at the levels that are observed for PGII when it is induced by homogalacturonan. Nonetheless, their presence (and importance) during early pathogenesis cannot be dismissed on this basis. Solidstate fermentation, which arguably represents a more natural culture condition than does conventional liquid fermentation, yields enzymes, including pectinases, that are substantially different biochemically from those produced in liquid culture (Acuna-Arguelles et al. 1995). The relevance of constitutively expressed EPGs in disease development should not be disregarded, especially as a constitutively expressed EPG of A. flavus has been linked to aggressiveness (Shieh et al. 1997) and since five of the six EPG genes cloned and characterized from the pathogen $B$. cinerea appear to be constitutively expressed (Wubben et al. 1999). The activity of these constitutive enzymes may, among other actions, serve to open the wall to the action of PMEs, which degrade methylesterfied pectins and consequently lower the extracellular $\mathrm{pH}$. This deesterification also serves to render the pectin substrate into the form that induces the production of the commercially important EPGs, such as A. niger PGI and PGII (De Vries and Visser 2001). PGC, though not as well characterized as PGI and II, has been examined in some detail
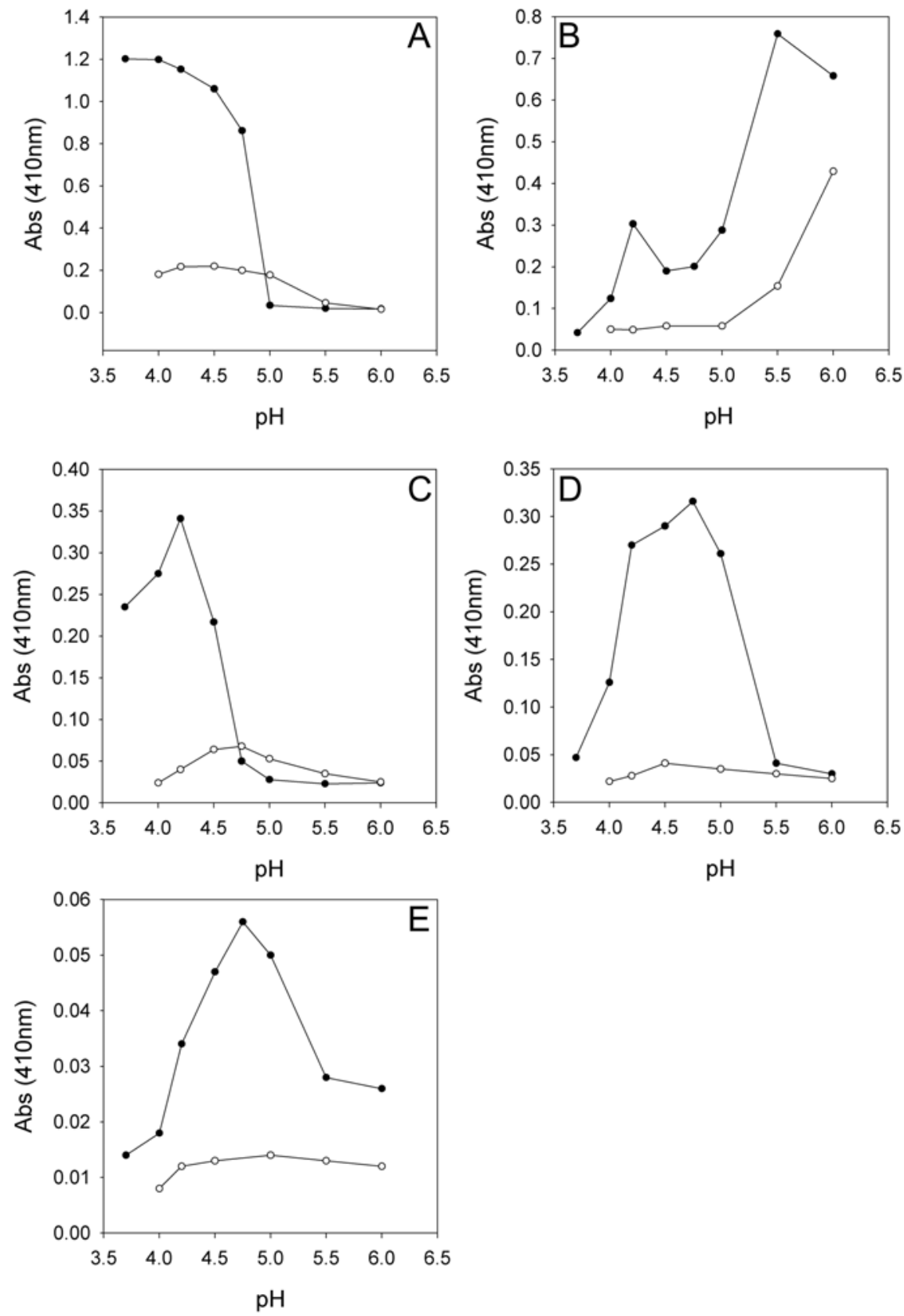

Fig. 3. Optimum pH profiles for the endopolygalacturonases used in the study, with added polygalacturonase-inhibiting protein (PGIP) fraction (open circles) and without PGIP (filled circles). A, PGA; B, PGB; C, PGC; D, PGI; and E, PGII. 
(Benen et al. 1999). Evidence indicates that PGC, which has a processive mode of action similar to that shown by PGI, may prefer regions in the pectin that are not easily accessible to PGI and PGII, such as the region containing rhamnogalacturonan II (Pařenicová et al. 2000). The various modes of action, expression patterns, and specificities demonstrated by the EPGs of a single fungus point toward a complex and sophisticated arsenal for maximizing the effect of attack on a plant cell wall.

The research presented in this paper provides another set of variables in the ongoing arms race between pathogens and their hosts. Early research had established a relatively simple picture for the roles of EPGs and PGIPs, in which the host PGIP inhibited the pathogen EPG, slowing down the degradation of the host cell wall and extending the half life of oligosaccharides responsible for the elicitation of the defense response (Cervone et al 1989; Darvill et al. 1992). This paper demonstrates that the effect of changes in $\mathrm{pH}$ upon the activity of PGs in the presence or absence of PGIPs is complex, with each EPG/PGIP combination showing its own dependence on $\mathrm{pH}$. At $\mathrm{pH}$ 5.0, the presence of PGIP-2 activates PGA and PGC. PGC shows higher levels of activation at $\mathrm{pH} 4.75$ but switches to inhibition below pH 4.75. PGA, on the other hand, is inhibited below pH 5.0 (Fig. 1B). As the interaction changes from inhibition to activation thru the "null point," it is unlikely that the PGIP dissociates from the PG and reattaches at a different location (for activation vs. inhibition), suggesting a sin- gle binding area for both activities. Since it is unlikely that activation can occur if the active cleft is covered, it lends support to the idea that the PGIP binds the underside of the PG (King et al. 2002).

The implications of this previously undescribed role for EPG/PGIP interactions have yet to be fully explored. Although $A$. niger is a saprophytic fungi and is not a biotrophic pathogen of $P$. vulgaris, it is proposed that the $\mathrm{pH}$-dependant activation illustrates a general fungal EPG characteristic traversing to the less well characterized phytopathogenic fungi. It is interesting to speculate that the interactions of PGA and PGC with PGIP during pathogenesis represent an evolutionary development wherein the fungus produces these two EPGs in response to the presence of host-plant PGIPs. For example, PGA has been described as a "scouting" enzyme (Pařenicová et al. 2000) that may have adapted to take early advantage of the presence of the host PGIP. Alternatively, perhaps the plant, by virtue of developing PGIPs capable of activation as well as inhibition, has enabled itself to more efficiently generate a steady-state concentration of biologically active oligogalacturonides, thus optimizing host defense responsiveness.

Recent work by Stotz and associates (2000) provides evidence that both EPGs and PGIPs are under selection pressure. PGIPs with completely different ranges of inhibitory activity may coexist within a host, as already indicated for bean PGIP (De Lorenzo et al. 2001; Desiderio et al. 1997). Thus, it is possible that different PGIPs can be called into play in different
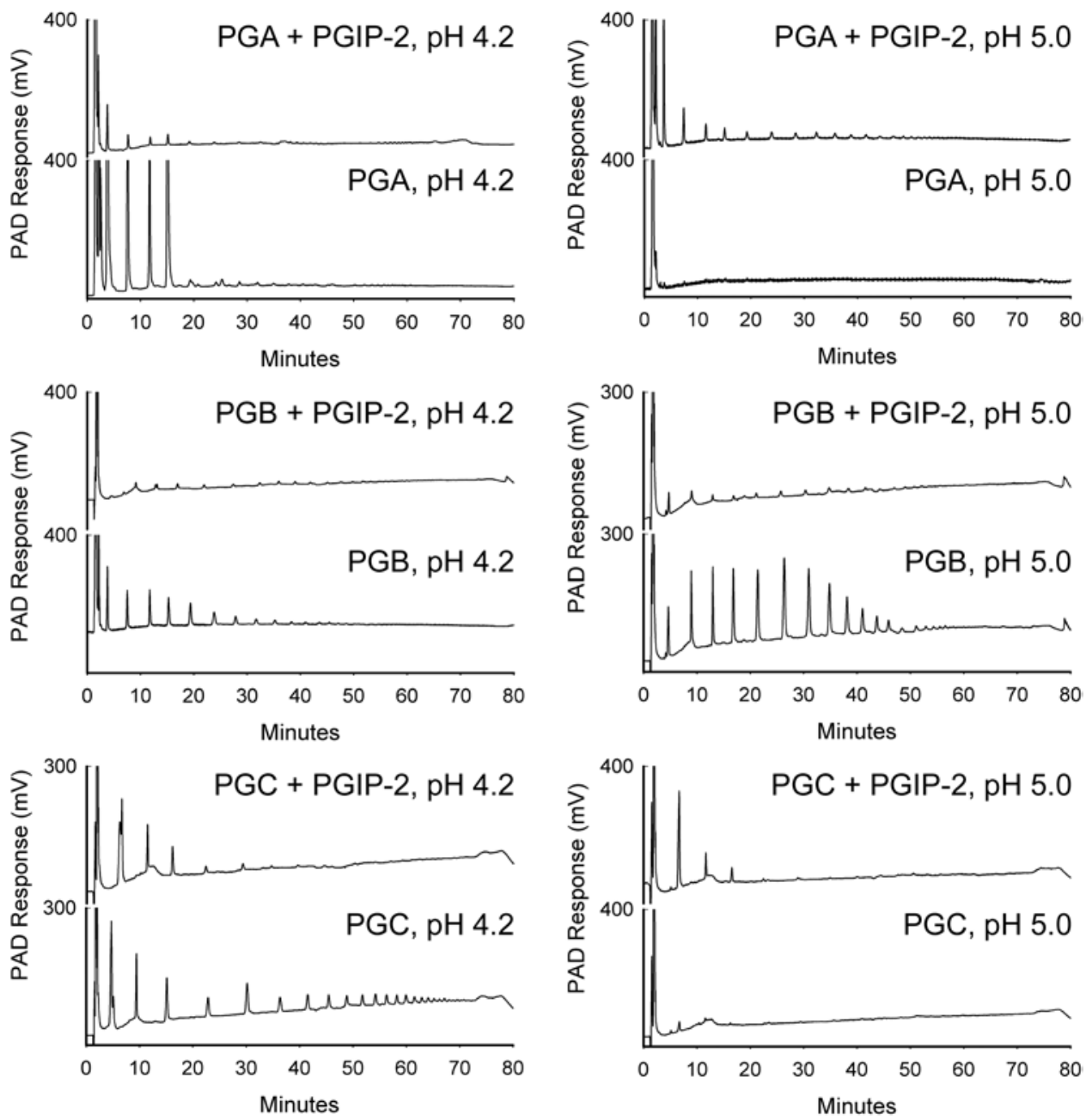

Fig. 4. Selected 1-h digests of homogalacturonan by Aspergillus niger polygalacturonase A (PGA), PGB, and PGC in the presence or absence of native bean polygalacturonase-inhibiting protein (PGIP)-2 at various $\mathrm{pH}$ levels. As indicated in the PGB pH 5.0 trace, each peak represents a galacturonic acid oligomer. Longer oligomers elute at higher retention times. 
tissues at different times, perhaps in response to intrusion from different pathogens. Changes in the apoplastic environment at the site of host-pathogen interaction that occur in response to the action of CWDEs such as PMEs, may alter the outcome of catalysis by the subsequent CWDEs produced. These effects may be specific for each host/pathogen combination. In this regard, the EPG/PGIP system appears to be more complicated and potentially more important than initially suspected.

Finally, it is apparent that under some circumstances, which can be assumed to occur in planta, PGIPs may increase the activity of certain EPGs. This suggests the possible need to revise the name of this class of plant cell wall protein from polygalacturonase-inhibiting proteins to polygalacturonase-binding proteins (from PGIP to PGBP).

\section{MATERIALS AND METHODS}

\section{PGIP extraction and purification.}

PGIP was extracted from Phaseolus vulgaris cv. Canellino pods using a method modified from Favaron and associates (1994). Healthy bean pods (1 kg) were homogenized in a blender with $500 \mathrm{ml}$ of acetone. The pulp was filtered through a nylon cloth, was squeezed dried and reblended with $300 \mathrm{ml}$ of acetone (repeated 3 times), and was allowed to completely dry out. The dried pulp was soaked in 1 liter of extraction buffer $(20 \mathrm{mM}$ sodium acetate, $\mathrm{pH} 6.0,1 \mathrm{M} \mathrm{NaCl})$ and was allowed to stir for $72 \mathrm{~h}$ at $4^{\circ} \mathrm{C}$.

The material was centrifuged at $9,000 \times g$ for $60 \mathrm{~min}$. The supernatant was recovered and filtered through Whatmann GF/A glass filter paper. The filtered supernatant was concentrated to $200 \mathrm{ml}$ in an Amicon stirred cell with a PM10 membrane and was subsequently dialyzed against $20 \mathrm{mM}$ sodium acetate ( $\mathrm{pH}$ 6.0) over a period of two days in standard cellulose dialysis tubing (12,000 to 14,000 molecular weight cutoff). The dialyzed sample was centrifuged for $45 \mathrm{~min}$ at $22,000 \times g$; the supernatant was recovered and concentrated to $200 \mathrm{ml}$ on an Amicon stirred cell with a PM10 membrane. Before proceeding to the chromatography, the concentrated sample was diluted 1:3 with $20 \mathrm{mM}$ sodium acetate, $\mathrm{pH}$ 5.0.

The protein content was separated by cation exchange chromatography using a 5-ml Econo-Pac high $\mathrm{S}$ cartridge (Bio-

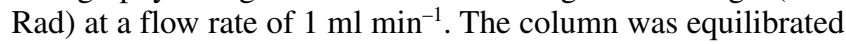
with buffer A (20 mM sodium acetate, $\mathrm{pH} 5.0)$ and eluted with buffer B (20 mM HEPES, pH 7.5, $300 \mathrm{mM} \mathrm{NaCl})$, using a linear gradient of $1 \%$ buffer B per minute. The 1-ml fractions were analyzed for inhibitor activity with an inhibition assay against $F$. moniliforme EPG.

Fractions exhibiting $F$. moniliforme EPG inhibition were pooled, and the PGIP-2 content was separated out by affinity chromatography on an $F$. moniliforme EPG affinity column, as reported by Desiderio and associates (1997). The sample was repeatedly loaded (six times) onto the column and eluted at 1

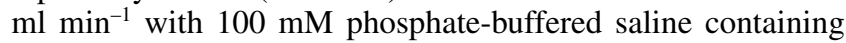
$130 \mathrm{mM} \mathrm{NaCl}$. The combined eluent was concentrated and dialyzed against sodium acetate (pH 5.0) on an Amicon stirred cell with a PM10 membrane and was subsequently separated through cation exchange chromatography using a HiTrap-S column (Amersham Bioscience, Uppsala, Sweden) at a flow rate of $1 \mathrm{ml} \mathrm{min}^{-1}$. Fractions were collected and analyzed for EPG inhibition.

This method was repeated with $720 \mathrm{~g}$ of $P$. vulgaris cv. Pinto etiolated hypocotyls.

\section{EPGs.}

EPGs from A. niger, including PGI, PGII, PGA, PGB, and PGC were a gift from J. Visser and A. Benen and were obtained as previously reported (Pařenicová et al. 1998, 2000).

\section{EPG inhibition or activation.}

All assays were performed using $10 \mu \mathrm{l}$ aliquots from appropriate chromatographic fractions of the cation exchange-purified PGIP-2. These were subsequently incubated for $1 \mathrm{~h}$ at room temperature with the various EPGs at $\mathrm{pH} 4.2, \mathrm{pH} 4.75$, and $\mathrm{pH} 5.0$ in $0.025 \%$ polygalacturonic acid as substrate buffered in $50 \mathrm{mM}$ sodium acetate. The most active PGIP fractions $(10 \mu \mathrm{l})$ guaranteed complete inhibition of $A$. niger I EPG at $\mathrm{pH}$ 5.0. A PGIP-2 fraction with the highest level of EPG inhibition was then used to inhibit each enzyme at $\mathrm{pH} 3.75,4.0,4.2,4.5$, $4.75,5.0,5.5$, and 6.0. The inhibition was quantified following incubation by spectrophotometrically $(410 \mathrm{~nm})$ measuring the decrease in the release of reducing sugars, using the PAHBAH ( $p$-hydroxybenzoic acid hydrazide) procedure (York et al. 1985). Controls containing no added EPGs were included to compensate for possible reducing sugars and native EPGs present in the chromatographic fractions. The potential influence of the chromatography buffer gradient on inhibition or enzyme activity were determined by including a control to assay for EPG activation or inhibition in a buffer gradient without PGIP. All data were determined in duplicate.

\section{MALDI-TOF MS.}

Samples were analyzed on a Hewlett Packard G2025A MALDI-TOF mass spectrometer (Palo Alto, CA, U.S.A.). The matrix used was a saturated sinapinic acid (3,5 dimethoxy-4hydroxy-trans-cinnamic acid) solution in $50 \%$ acetonitrile. Equal volumes of sample and matrix (approximately $1.0 \mu \mathrm{l}$ ) were loaded onto the probe and were dried under vacuum. The laser energy ranged from 10 to $14 \mu \mathrm{J}$.

\section{HPAEC and pulsed amperometric detection analysis.}

The OGA profile in $200 \mu$ of each of the above described 1$h$ digests were obtained by anion exchange chromatography using a Dionex (Sunnyvale, CA, U.S.A.) AL50 HPLC and a Dionex CarboPAC PA1 column coupled to a Dionex pulsed amperometric detector, as previously described (Cook et al. 1999).

\section{ACKNOWLEDGMENTS}

This research was supported in part by the United States Department of Energy (DOE)-funded Center for Plant and Microbial Complex Carbohydrates (DE-FG05-93ER20097) and DOE grant DE-FG02-96ER20221 (to P. Albersheim). We thank A. Jones and E. Fletcher for excellent technical assistance.

\section{LITERATURE CITATIONS}

Acuna-Arguelles, M. E., Gutierrez-Rojas, M., Viniegra-Gonzalez, G., and Favela-Torres, E. 1995. Production and properties of three pectinolytic activities produced by Aspergillus niger in submerged and solid-state fermentation. Appl. Microbiol. Biotechnol. 43:808-814.

Benen, J. A. E., Kester, H. C. M., Pařenicová, L., and Visser, J. 1996. Kinetics and mode of action of Aspergillus niger polygalacturonases. In: Pectins and Pectinases. J. Visser and A. G. J. Voragen, eds. Elsevier Science B.V., Amsterdam.

Benen, J. A. E., Kester, H. C. M., and Visser, J. 1999. Kinetic characterization of Aspergillus niger N400 endopolygalacturonases I, II and C. Eur. J. Biochem. 259:577-585.

Bergmann, C. W., Stanton. L., King, D., Clay, R. P., Kemp, G., Orlando, R., Darvill, A., and Albersheim, P 2001. Recent observations on the specificity and structural conformation of the polygalacturonase-polygalacturonase-inhibiting protein system. Pages 277-291 in: Proceedings of the 2001 Pectins and Pectinases Conference, Rotterdam. Kluwer Academic Publishers, Dordrecht, The Netherlands.

Centis, S., Guillas, I., Séjalon, N., Esquerré-Tugayé, M. T., and Dumas, B. 1997. Endopolygalacturonase genes from Colletotrichum lindemuthianum: Cloning of CLPG2 and comparison of its expression to that of CLPG1 during saprophytic and parasitic growth of the fungus. Mol. Plant-Microbe Interact. 10:769-775. 
Cervone, F., De Lorenzo G., Degrà, L., Salvi, G., and Bergami, M. 1987. Purification and characterization of a polygalacturonase-inhibiting protein from Phaseolus vulgaris L. Plant Physiol. 85:631-637.

Cervone, F., Hahn, M. G., De Lorenzo, G., Darvill, A., and Albersheim, P. 1989. Host-pathogen interactions XXXIII. A plant protein converts a fungal pathogenesis factor into an elicitor of plant defense responses. Plant Physiol. 90:542-548.

Cooper, R. M. 1983. The mechanisms and significance of enzymic degradation of host cell walls by parasites. Pages 101-135 in: Biochemical Plant Pathology. J.A. Callow, ed. John Wiley and Sons, New York.

Cook, B. J., Clay, R. P., Bergmann, C. W., Albersheim, P., and Darvill, A. G. 1999. Fungal polygalacturonases exhibit different substrate degradation patterns and differ in their susceptibilities to polygalacturonase inhibiting proteins. Mol. Plant-Microbe Interact. 12:703711.

Côté, F., and Hahn, M. G. 1994. Oligosaccharins: Structures and signal transduction. Plant Mol. Biol. 26:1379-1411.

Darvill, A., Augur, C., Bergmann, C., Carlson, R. W., Cheong, J.-J., Eberhard, S., Hahn, M. G., Ló, V.-M., Marfà, V., Meyer, B., Mohnen, D., O’Neill, M. A., Spiro, M. D., van Halbeek, H., York, W. S., and Albersheim, P. 1992. Oligosaccharins-Oligosaccharides that regulate growth, development and defense responses in plants. Glycobiology 2:181-198.

Darvill, A., Bergmann, C., Cervone, F., De Lorenzo, G., Ham, K.-S., Spiro, M. D., York, W. S., and Albersheim, P. 1994. Oligosaccharins involved in plant growth and host-pathogen interactions. Biochem. Soc. Symp. 60:89-94.

De Lorenzo, G., and Ferrari, S. 2002. Polygalacturonase-inhibiting proteins in defense against phytopathogenic fungi. Curr. Opin. Plant Biol. $5: 1-5$.

De Lorenzo, G., D’Ovidio, R., and Cervone, F. 2001. The role of polygalacturonase-inhibiting proteins (PGIPs) in defense against pathogenic fungi. Annu. Rev. Phytopathol. 39:313-335.

Desiderio, A., Aracri, B, Leckie, F., Mattei, B., Salvi, G., Tigelaar, H., Van Roekel, J. S. C., Baulcombe, D. C., Melchers, M. S., De Lorenzo, G., and Cervone, F. 1997. Polygalacturonase-inhibiting proteins (PGIPs) with different specificities are expressed in Phaseolus vulgaris. Mol Plant-Microbe Interact. 10:852-860.

De Vries, R. P., and Visser, J. 2001. Aspergillus enzymes involved in degradation of plant cell wall polysaccharides. Microbiol. Mol. Biol. Rev. 65(4):497-522.

Di Matteo, A., Federici, L., Salvi, G., Johnson, K. A., Savino, C., De Lorenzo, G., Tsernoglou, D., and Cervone, F. 2003. The crystal structure of polygalacturonase-inhibiting protein (PGIP), a leucine-rich repeat protein involved in plant defense. Proc. Natl. Acad. Sci. U.S.A. 100(17):10124-10128

Di Pietro, A., and Roncero, M. I. G. 1996. Endopolygalacturonase from Fusarium oxysporum f sp lycopersici: Purification, characterization, and production during infection of tomato plants. Phytopathology 86:1324-1330.

Favaron, F., D’Ovidio, R. D., Porceddu, E., and Alghisi, P. 1994. Purification and molecular characterization of a soybean polygalacturonaseinhibiting protein. Planta 195:80-87.

Frederici, L., Caprari, C., Savino, C., Di Matteo, A., De Lorenzo, G., Cervone, F., and Tsernoglou, D. 2001. Structural requirements of endopolygalacturonase for the interaction with PGIP (polygalacturonase-inhibiting protein). Proc. Natl. Acad. Sci. U.S.A. 98:1342513430.
Hoffman, R. M., and Turner J. G. 1982. Partial purification of proteins from pea leaflets that inhibit Ascochyta pisi endopolygalacturonase. Physiol. Plant Pathol. 20:173-187.

Jones, D. A., and Jones, J. D. G. 1997. The role of leucine-rich repeat proteins in plant defences. Adv. Bot. Res. 24:89-167.

Jones, T. M., Anderson, A. J., and Albersheim, P. 1972. Host-pathogen interactions IV. Studies on the polysaccharide-degrading enzymes secreted by Fusarium oxysporum f. sp. lycopersici. Physiol. Plant Pathol. 2:153-166.

Kemp, G., Bergmann, C. W., Clay, R., Van der Westhuizen, A. J., and Pretorius, Z. A. 2003. Isolation of a polygalacturonase-inhibiting protein (PGIP) from wheat. Mol. Plant-Microbe Interact. 16:955-961.

King, D., Bergmann, C., Orlando, Benen, J. A. E., Kester, H. C., and Visser, J. 2002. Use of amide exchange mass spectrometry to study conformational changes within the endopolygalacturonase II-homogalacturonanpolygalacturonase inhibiting protein system. Biochemistry 41:1022510233.

Knogge, W. 1996. Fungal infection of plants. Plant Cell 8:1711-1722.

Lafitte, C., Barthe, J. P., Montillet, J. L., and Touzé, A. 1984. Glycoprotein inhibitors of Colletotrichum lindemuthianum endopolygalacturonase in near isogenic lines of Phaseolus vulgaris resistant and susceptible to anthracnose. Physiol. Plant Pathol. 25:39-53.

Pařenicová, L., Benen, J. A. E., Kester, H. C. M., and Visser, J. 1998. PgaE encodes a forth member of the endopolygalacturonase gene family from Aspergillus niger. Eur. J. Biochem. 251:72-80.

Pařenicová, L., Bene, J. A. E., Kester, H. C. M., and Visser, J. 2000. PgaA and pgaB encode two constitutively expressed endopolygalacturonases of Aspergillus niger. Biochem. J. 345:637-644.

Sharrock, K., and Labavitch, J. M. 1994. Polygalacturonase inhibitors of 'Bartlett' pear fruits: Differential effects of Botrytis cinerea polygalacturonase isozymes, and influence on products of fungal hydrolysis of pear cell walls and on ethylene induction in cell culture. Physiol. Mol. Plant Pathol. 45:305-319.

Shieh, M.-T., Brown, R. L., Whitehead, M. P., Cary, J. W., Cotty, P. J., Cleveland, T. E., and Dean, R. A. 1997. Molecular genetic evidence for the involvement of a specific polygalacturonase, P2c, in the invasion and spread of Aspergillus flavus in cotton bolls. Appl. Environ. Microbiol. 63:3548-3552.

Stotz, H. U., Contos, J. J. A., Powell, A. L. T., Bennett, A. B., and Labavitch, J. M. 1994. Structure and expression of an inhibitor of fungal polygalacturonases from tomato. Plant Mol. Biol. 25:607-617.

Stotz, H. U., Bishop, J. G., Bergmann, C. W., Koch, M., Albersheim, P., Darvill, A. G., and Labavitch, J. M. 2000. Identification of target amino acids that affect interactions of fungal polygalacturonases and their plant inhibitors. Physiol. Mol. Plant Pathol. 56:117-130.

Toubart, P., Desiderio, A., Salvi, G., Cervone, F., Daroda, L., De Lorenzo, G., Bergmann, C., Darvill, A. G., and Albersheim, P. 1992. Cloning and characterization of the gene encoding the polygalacturonase-inhibiting protein (PGIP) of Phaseolus vulgaris L. Plant J. 2:367-373.

Wubben, J. P., Mulder, W., Ten Have, A., Van Kan, J. A. L, and Visser, J. 1999. Cloning and partial characterization of endopolygalacturonase genes from Botrytis cinerea. Appl. Environ. Microbiol. 65:1596-1602.

Yakoby, N., Kobiler, I., Dinoor, A., and Prusky, D. 2000. pH regulation of pectate lyase secretion modulates the attack of Colletotrichum gloeosporioides on avocado fruits. App. Environ. Microbiol. 66:1026-1030.

York W. S., Darvill A. G., McNeil M., Stevenson T. T., and Albersheim P. 1985. Isolation and characterization of plant cell walls and plant cell wall components. Method Enzymol. 118:3-40. 